\title{
UAE University Students' Awareness of Using the Writing Center
}

\author{
Ghadah Al Murshidi ${ }^{1} \&$ Kholood Al Abd ${ }^{2}$ \\ ${ }^{1}$ Department of Curriculum and Instruction, College of Education, United Arab Emirates University, United \\ Arab Emirates \\ ${ }^{2}$ Department of Linguistics and Translation, Humanities and Social Sciences College, United Arab Emirates \\ University, United Arab Emirates \\ Correspondence: Ghadah Al Murshidi, Department of Curriculum and Instruction, College of Education, United \\ Arab Emirates University, United Arab Emirates. E-mail: g_almurshidi@uaeu.ac.ae
}

Received: April 20, 2014 Accepted: May 23, 2014 Online Published: May 28, 2014

doi:10.5539/hes.v4n3p58 URL: http://dx.doi.org/10.5539/hes.v4n3p58

\begin{abstract}
Writing has always been regarded as playing a prominent role in learning a second language. UAE university writing center provides a key support service within the institution, and as such must find ways to evaluate the impact of the instruction they provide. However, many studies of tutorial effectiveness lack adequate analyses of tutorial services and of both student and tutor awareness and outcomes. The purpose of the study is to explore the effectiveness of the writing center and its proposed services to improve students' academic writing skills. The study combined quantitative and qualitative strategies involving surveying 50 students followed by in-depth interview with the supervisor of the UAEU's writing center. Some major findings are that the study indicated that some students who visit the writing center are not aware of how to use it effectively. The study shows that $76 \%$ of students stated that the role of the writing center is to edit their assignments. The study indicates that $32 \%$ of students who visited the writing center were encouraged by their instructors to visit the writing center. This study implies some strategies to raise the students' awareness of the writing center purpose and services.
\end{abstract}

Keywords: writing center, writing center services, tutors, students' awareness, academic writing

\section{Introduction}

Writing is important skill in the academic life especially in higher education system. It is a measure of academic achievement that drives learning and promotes intellectual and personal development. One of the writing center goals is helping students to learn and develop their writing skills. Writing centers gives students access and assistance on their papers and their ongoing projects in their educational institutions such as UAE University (UAEU). UAEU's writing center was established in 2004. The writing center mission is to help foundation students to learn and practice academic writing to become better writers. The writing center holds regular writing workshops and provides practice materials for all foundation writing courses, ESP and the IELTS writing exam. The writing center is staffed by teachers from the English, Arabic and ESP programs of the University Foundation Programs (UFP), and peer tutors recruited from different UAEU faculties.

Writing centers have collaborative teams which they call tutors. Tutors may be peers, professionals, graduate students, part time instructors or teachers. They meet individually with writers in the writing center either briefly (e.g., fifteen to twenty minutes) or for more extended periods of time (typically, an hour) to help a particular writer's concerns. UAEU's writing center provides different services such as workshops, promoting student engagement in writing and website. Students can work with tutors on any aspect of academic writing tasks (e.g., organization, proofreading). Tutors assist students in preparing their CVs or helping them with creative writing.

\section{Literature Review}

Writing centers were first established in 1969 and were called writing labs (North, 1984). "The writing center has developed over the decades into a sophisticated service, supporting students in first-year writing programs and beyond, across the full range of disciplines" (Thonus, 2002). Many scholars discuss the concept of the writing center. (Harris, 1989, p. 1) states that "writing centers exist in a variety of shapes, sizes, and settings". A writing center is a good source for learning and improving writing skills among the students. Harris claimed, "Working with student writing is one of academia's most labor-intensive activities". Evaluating a writing center's success is important. In universities, in particular, evaluation can play an important role in a university's 
improvement plans without putting anyone in a position to promise that writing center visits lead to increases in students' test scores. Evaluation can be made by comparing the grades, motivation, and attitudes of the students who attend the writing center with those of students who do not attend. According to a study made by the supervisor of the writing center, which was conducted on 140 UFP (University Foundation Program) level 3 students among seven level 3 writing classes. Participants were divided into two groups, an experimental and control group, 80 and 60 students respectively. Throughout 14 weeks of one semester, both groups completed 8 writing portfolio tasks. The results indicate that both groups made significant gains throughout the semester. However, the results also indicate that the experimental group is better than the control group. This shows that 8 sessions at the writing center did have an impact on students' writing scores.

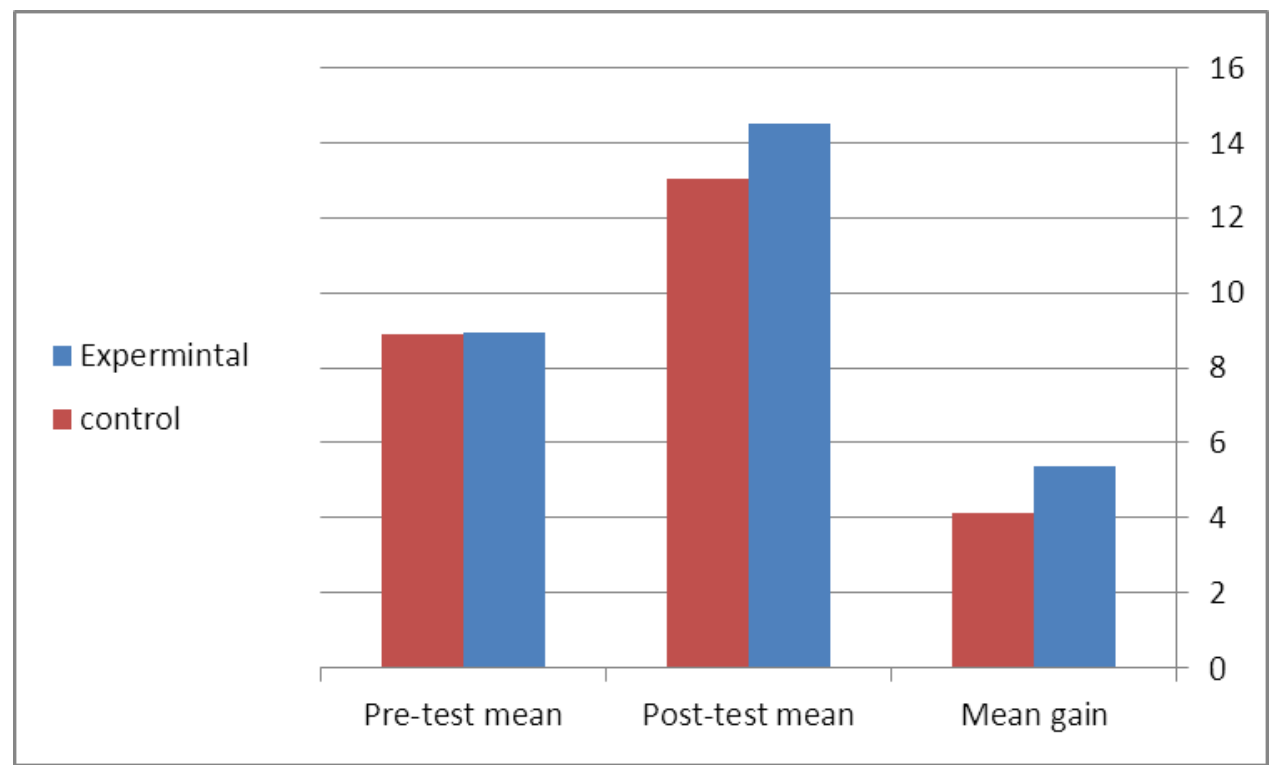

Figure 1. Results of a UAEU UFP study of gains after 8 portfolio writing tasks

\section{Methodology}

The main purpose of this study is to explore the students' awareness of using the writing center services effectively. In this study, the researchers utilized mixed method research design that combines quantitative and qualitative strategies involving surveying 50 students followed by in-depth interview with the supervisor of the UAEU's writing center. The collected data includes:

\subsection{A Questionnaire}

The number of participants is around 50 students, who are enrolled in the University Foundation Program and different UAEU colleges.

\subsection{In-Depth Interview with the Supervisor of The UAEU's Writing Center}

The researchers interviewed the supervisor of the writing center and asked her some questions to measure the effectiveness of the writing center, to know what kind of services that the writing center provides for the students and to investigate if the students are aware of how to use the writing center services effectively. The interview questions are open, allowing the respondent to elaborate on issues under discussion. The interview's questions are:

1) Are the students aware of the writing center purpose?

2) Do the students use the writing center services effectively?

Effectiveness means that adequateness to accomplish a purpose or producing the intended or expected result. The main purpose of having a writing center in UAEU is to assist the students to improve their academic writing. More studies are needed to measure the effectiveness of the writing center, and achievement of its' proposed purpose. 


\section{Results and Discussion}

The questions of the questionnaire and its' results are shown below:

Table 1. Question 1 (Is this your first visit to the writing center?)

\begin{tabular}{lll}
\hline Answer Choices & Yes & $24 \%$ \\
\hline Percentage & No & $76 \%$ \\
\hline
\end{tabular}

Table 2. Question 2 (What or who encouraged you to visit the writing center?)

\begin{tabular}{lllll}
\hline Answer Choices & $\begin{array}{l}\text { My instructor } \\
\text { suggested it }\end{array}$ & $\begin{array}{l}\text { My instructor } \\
\text { required it }\end{array}$ & $\begin{array}{l}\text { My friend } \\
\text { recommended it }\end{array}$ & Other \\
\hline Percentage & $22 \%$ & $10 \%$ & $64 \%$ & $4 \%$ \\
\hline
\end{tabular}

Table 3. Question 3 (How often did you visit the writing center the last two semesters?)

\begin{tabular}{lllll}
\hline Answer Choices & Once & $2-3$ times & $4-5$ times & 6 times or more \\
\hline Percentage & $14 \%$ & $36 \%$ & $30 \%$ & $20 \%$ \\
\hline
\end{tabular}

Table 4. Question 4 (Which type of help did you asked for in the writing center?)

\begin{tabular}{llllll}
\hline Answer Choices & Grammar & Vocabulary & Spelling & CV & Other \\
\hline Percentage & $48 \%$ & $12 \%$ & $20 \%$ & $12 \%$ & $8 \%$ \\
\hline
\end{tabular}

Table 5. Question 5 (Do you know about writing center opening hours?)

\begin{tabular}{lll}
\hline Answer Choices & Yes & No \\
\hline Percentage & $72 \%$ & $28 \%$ \\
\hline
\end{tabular}

Table 6. Question 6 (Do you agree with the statement: The role of the writing center is to write the assignments for students?)

\begin{tabular}{llll}
\hline Answer Choices & Agree & Disagree & I don't know \\
\hline Percentage & $24 \%$ & $72 \%$ & $4 \%$ \\
\hline
\end{tabular}

Table 7. Question 7 (Do you agree with this statement: the role of the writing center is to edit the assignments of the students?)

\begin{tabular}{llll}
\hline Answer Choices & Agree & Disagree & I don't know \\
\hline Percentage & $76 \%$ & $20 \%$ & $4 \%$ \\
\hline
\end{tabular}

Table 8. Question 8 (Do you know about the online exercises that the writing center has on its website?)

\begin{tabular}{lll}
\hline Answer Choices & Yes & $30 \%$ \\
\hline Percentage & No & $70 \%$ \\
\hline
\end{tabular}

Table 9. Question 9 (Did you access the writing center website and try to do the exercises offered online?)

\begin{tabular}{lll}
\hline Answer Choices & Yes & $8 \%$ \\
\hline Percentage & No & $92 \%$ \\
\hline
\end{tabular}


Table 10. Question 10 (If you answered yes to the question above, did you bring any of these online exercises to the writing center for correction?)

\begin{tabular}{lll}
\hline Answer Choices & Yes & No \\
\hline Percentage & $4 \%$ & $96 \%$ \\
\hline
\end{tabular}

Table 11. Question 11(Overall, how would you rate the tutoring services of the writing center?)

\begin{tabular}{lllll}
\hline Answer Choices & Excellent & Good & Fair & Poor \\
\hline Percentage & $68 \%$ & $32 \%$ & $0 \%$ & $0 \%$ \\
\hline
\end{tabular}

The researcher analyzed the questionnaire and found that the majority of students who visited the writing center have been encouraged by their friends to visit it. $32 \%$ of students indicated that their instructors suggested visiting the writing center to improve their writing skills. Moreover, $72 \%$ of students stated their knowledge of the writing center opening hours. However, $28 \%$ of students indicated that they do not know about the writing center opening hours. When the researcher made an interview with the supervisor of the writing center and asked her about their objectives, she said that the main goal of the writing center is to help students learn and improve their writing skills, not helping them in editing or writing their assignments. However, the results of the survey show that $76 \%$ of students agreed that the role of the writing center is to edit their papers. The survey shows that the majority of students ( $48 \%$ ), who come to the writing center, come to check their grammatical mistakes. $20 \%$ of the students visit the writing center to check their spelling mistakes as shown in Figure 2.

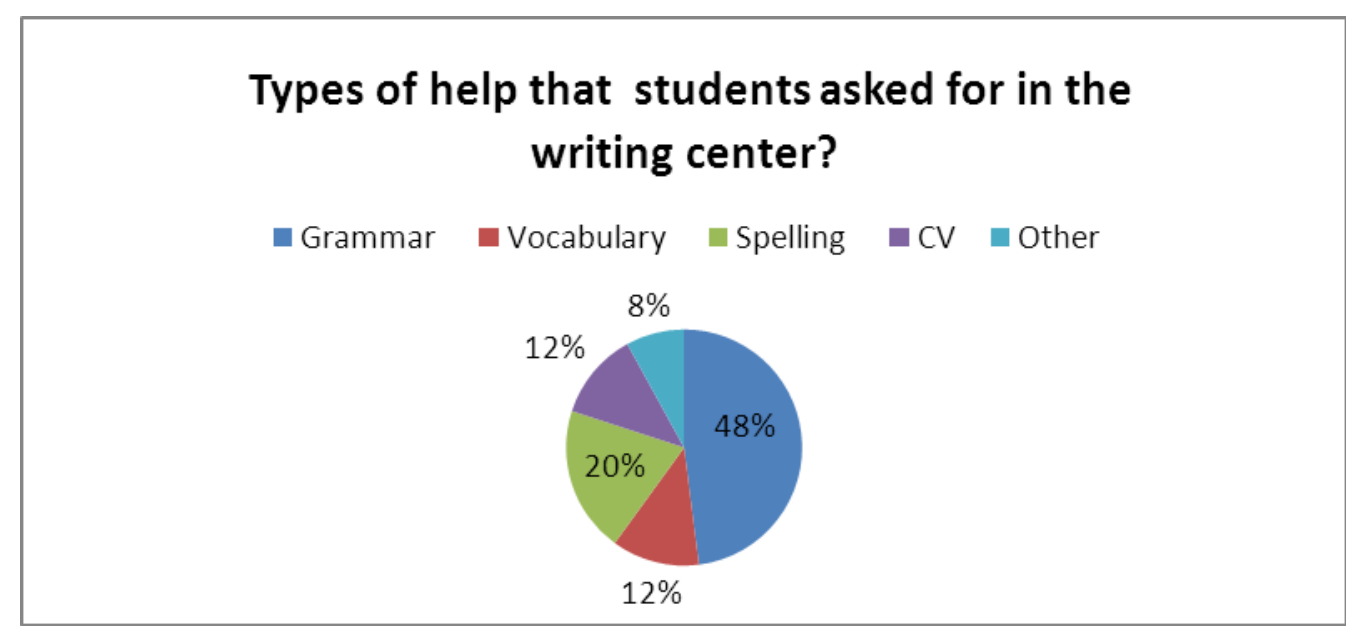

Figure 2. Assistant forms students ask in the writing center

The writing center provides materials and online exercises for students to help them how to write. According to the questionnaire, the percentage of the students who do not know about these online exercises was $92 \%$. During the interview, the researcher asked the supervisor of the writing center about these online exercises. The supervisor said that the online exercises are for University Foundation Program students only. It helps them in their writing. The researcher also asked her how the students get responses about the exercises. The supervisor stated that the student can printout the exercises and bring them to the writing center to get feedback from tutors. The researcher checked the online exercises which are in the writing center's website and found that there are no instructions on each page of this exercises that indicate the facility of printing out the papers and checking them by tutors in the writing center. The instructions are stated on the first page of the online exercises which is unclear to the reader. The researcher also found that $68 \%$ of students rate the tutoring services of the writing center as excellent, whereas $32 \%$ of students rate the tutoring services as good. This means the users of the writing center are satisfied from the services that provides for them. But, not all of them are aware of how to use the services effectively. The majority of students think that the writing center role is editing their assignments. However, the role of the writing center is to assist the students in their writing assignments in order to improve 
their academic writing.

Regarding the interview results, the director of the writing center stated that the majority of visitors come from UFP, undergraduate students and some graduate students (Director of the writing center, personal communication, September 15, 2013). UAE University writing center is self-access learning resource that is open to all UAEU students and staff. Students can choose to visit the writing center as often as they like, and at their convenient time. Since 2004, "the writing center has been assisting members of the UAEU community to help to become better writers by offering expert writing assistance in a student-centered and collaborative learning environment" (Director of the writing center, personal communication, September 15, 2013). According to Director of the writing center (2013), the writing center offers many services. For instance, it helps faculty and foundation students learn more about writing and helps them to become better writers. Tutors work effectively when they are working in a supportive environment of the writing center. The tutor's role is to help students, not to lecture or repeat available information that is in their textbooks. Writing center goal is to help students learn how to be independent and how to correct their own mistakes (Director of the writing center, personal communication, September 15, 2013).

The director of the writing center stressed that the writing center is not a place for editing. The tutors' function is to help students how to correct their own mistakes independently by showing them their errors. She also claimed that students need to bring their papers, outlines or any work that they need help with from tutors and tell the tutors what kind of help they need. This is the first step of how students could improve writing skill in their academic community. The students could also develop their skills in writing without relying on tutors, by writing and checking their grammatical errors or vocabularies using online programs or dictionaries. The purpose of having a writing center in academic institutions is to help students to develop their writing skills and to encourage them to be better writers in the future. The director also mentioned that every month the writing center publishes a magazine which includes students' work such as poems.

\section{Conclusion}

The study indicated that some students who visit the writing center are not aware of how to use it effectively. The study shows that $76 \%$ of students stated that the role of the writing center is to edit their assignments. Whereas, the director of the writing center said that the role of the writing center is to help students how to write and develop their writing skills. This result shows contradiction among the students' and the director's perception and awareness of the writing center purpose and use.

The study indicates that $76 \%$ of students who visited the writing center have been encouraged by their friends. $32 \%$ of students were encouraged by their instructors to visit the writing center. This result raises a question of the instructors' knowledge of the writing center and its' usefulness. Also, the questionnaire shows that few students know about the writing center's website, but they do not know that they may ask for feedback for their online exercise from tutors. The issue is that the website does not have clear instructions on the tutors' feedback option. $70 \%$ of students do not know about the writing center's website, which means that the writing website is not used fully by the students.

The study is limited because of the small number of participants who answered the questionnaire. Increasing the sample size of the participants for the survey is needed for future research. Also, triangulating the data by conducting in-depth interviews with students that assess their knowledge and understanding of the center's services will provide detailed information regarding a small group of people (Patton, 2002). In other words, qualitative research illuminates the individual differences between participants in a study, and creates a more detailed portrait of the findings. In future research, the study could be replicated by revising the questionnaire to be more detailed and researching the instructors' perceptions in-depth regarding the purpose, significance and services of the writing center. The study implies some strategies to raise the students' awareness of the writing center purpose and services such as creating an effective website for the writing center for all UAEU students and members, and send emails each week to let students to be aware of the services offered by the Writing Center.

\section{References}

Harris, M. (1980). The Roles a Tutor Plays: Effective Tutoring Techniques. English Journal, 69, 62-65. http://dx.doi.org/10.2307/81638.3343353

Harris, M. (1989). The Writing Center and Tutoring in WAC Programs. English Journal, 10, 109-113.

Mohr, E. (1998). Researching the Effectiveness of a Writing Center. Retrieved August 5, 2013, from http://files.eric.ed.gov/fulltext/ED419233.pdf 
Nordquist, R. (2006). About.com Grammar \& Composition. Writing Center. Retrieved July 22, 2013, from http://grammar.about.com/od/tz/g/Writing-Center.htm

North, S. (1984). The Idea of a Writing Center. College English, 46, 433-446. http://dx.doi.org/10.2307/377047

Thonus, T. (2002). Tutor and Student Assessments of Academic Writing Tutorials: What is "Success"? Science Direct. Retrieved June 10, 2013, from http://www.sciencedirect.com/science/article/pii/S1075293503000023

Whitehouse, E. (2013). The writing center staff handbook. Writing center, 3-4. Director of the writing center, personal communication, September 15, 2013.

\section{Copyrights}

Copyright for this article is retained by the author(s), with first publication rights granted to the journal.

This is an open-access article distributed under the terms and conditions of the Creative Commons Attribution license (http://creativecommons.org/licenses/by/3.0/). 